\title{
Deuda Externa y \\ Comercio Exterior
}

RAFAEL CARVAJAL

Profesor Universidad del Valle

\section{Introducción}

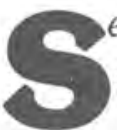

e ha insistido bastante en los

aspectos negativos que sobre el

bienestar y el desarrollo

latinoamericanos presenta la crisis de

endeudamiento externo. Evidentemente,

un enfoque de esa naturaleza conduce a conclusiones poco menos que

catastróficas, por lo demás, debidamente sustentadas. Por fortuna, es posible

argumentar que los datos seleccionados y el diagnóstico son la resultante de ordenar la reflexión a partir de ángulos de enfoque muy apropiados para revelar una determinada faz del problema, pero así mismo, esconde o dice poco de otros igualmente pertinentes. En nuestro caso parece que hemos privilegiado un análisis empeñado en responder a una sola pregunta: (el ángulo de enfoque) ¿Cómo nos afecta el endeudamiento? sobre esa base se calibra la trascendencia y la magnitud depresiva de la crisis externa hasta llegar a declarar que la de los 80 fue una década perdida para el desarrollo, peor aún: hacia el siglo XXI persisten dudas y graves interrogantes.
Ante este sombrío panorama es válido y conveniente reformular la pregunta de base; - ¿Para qué nos puede servir la crisis de endeudamiento externo?

Responderla conducirá necesariamente a una nueva selección de datos que bien pueden ser el punto de partida para plantear alternativas a la crisis. De eso se trata, esta es la perspectiva que anima los siguientes breves comentarios sobre la relación entre deuda externa y comercio exterior. El tratamiento abordará varios puntos:

El primero, tiene que ver con aspectos básicos para enfocar desde sus elementos el nexo entre deuda externa y comercio exterior. El segundo punto, versa sobre la evolución de los efectos y características de la deuda como problema económico internacional a todo lo largo de la década. Finalmente, se procederá a un breve examen de la visión cepalista del comercio exterior por cuanto se reconoce la influencia de este paradigma en las estrategias de desarrollo latinoamericano. 


\section{Lo sustantivo de la crisis}

$\mathrm{E}$

ste primer punto destaca lo siguiente: ¡la deuda hay que pagarla!; son cada vez más los factores y circunstancias que así lo indican. En breve, la propuesta de la ortodoxia marxista no halló viabilidad política en el subcontinente, quizá gozó de buena opinión pública pero no de efectivos apoyos políticos" $"$. Así mismo, los SWAPS como alternativa para pagar la deuda a precio de mercado y convertirla en capital no halló viabilidad económica.

Es obvio: los capitales internacionales tienen más interés en los propios países desarrollados, en el sudeste asiático, Europa del Este y la URSS ${ }^{2 a}$. Finalmente y quizá la razón de más peso, no pagar la deuda es una opción que a nadie conviene. Podría ser la bancarrota del sistema financiero internacional en momentos que no se dispone de otra infraestructura que canalice capitales y financie proyectos de inversión y desarrollo en los que la propia Latinoamérica está interesada.

Aunque elemental, no sobra recordar que la deuda tiene que pagarse en dólares. Es la divisa internacional por excelencia. De igual modo, quien tiene que responder ante los acreedores son los Estados latinoamericanos. Esto quiere decir que incluso las deudas externas del sector privado están a cargo de los Estados centrales. Como es bien sabido, esto es resultado de la nacionalización de la deuda que obtuvieron los acreedores en la primera ronda

(1) La propuesta del marxismo ortodoxo argumentó el repudio de una sustancial porción de la deuda: consultor, Julio Silva Colmenares. "Deuda externa: crisis y confrontacion", Ediciones Alborada.

(2) Para más información consultar "Un Menú de Opciones para los paises deudore", de Robert Devlin. Investigador de la Cepal, publicado en "Economía Colombiana" Nos. 211212, Noviembre-Diciembre 1988. de negociaciones ${ }^{\prime 3}$. La conclusión es clara: los Estados latinoamericanos están en la imperiosa necesidad de comprometer sus esfuerzos en promover exportaciones y obtener control de divisas. Sólo de esta forma asegurarán una balanza de pagos sin sesgos recesivos. Además, en adición al pago de la deuda, se necesitan divisas para financiar los proyectos de apertura económica y reconversión industrial. Bajo estas condiciones la deuda externa aparece con una nueva faceta: puede ser una estimulante oportunidad de reformular el patrón de inserción en la economía mundial - nuevos productos, nuevos mercados - y de paso, rediseñar las condiciones de acumulación interna, más aún, cuando ya se han agotado los alcances del modelo cepalista.

\section{El perfil internacional de la deuda en los años 80.}

¿Qué se ha hecho en la dirección que se acaba de señalar? Hasta el momento muy poco, pero es prematuro enjuiciar desde ya un proyecto que forzosamente sólo puede presentar rendimientos económicos a mediano y largo plazos. Por lo pronto la magnitud de la crisis plantea inexorablemente el problema de la coyuntura de pagos; fue así como se restringieron las importaciones, se devaluaron las monedas, se negociaron nuevos préstamos, etc., lo que acompañado de la reactivación económica de Estados Unidos y Europa permitió obtener en los últimos años un significativo superávit comercial que ha alcanzado la cifra de $\$ 16.000$ millones $^{(4)}$. Sin

(3) Consultar "El Negocio de la Deuda Externa", Jacqueline Robbick. Ancora editores. 1990, pág. 87.

(4) Consultar "Deuda Externa en América Latina" y "El Vinculo Deuda Externa-Comercio". Informes del Sela publicaciones en "Economia Colombiana" Nos. 211-212 de 1988. 
embargo, una porción muy significativa de estos ingresos ha debido destinarse al pago de amortizaciones y servicios (en algunos países con porcentajes próximos al $60 \%$ ) de modo que se ha creado una situación en la que se ha roto el nexo entre comercio y desarrollo. Este es precisamente el argumento de fondo para calificar los 80 como una década perdida para el desarrollo. Pero hay algo más, el pago negociado (al menos de los principales deudores) junto al fortalecimiento de las reservas bancarias internacionales ha modificado sustancialmente el perfil internacional de la deuda. De crisis financiera internacional en 1982, hoy, en 1990 es sólo una crisis latinoamericana $^{\mid{ }^{5} \text {. }}$. Esto es justamente el resultado de una estrategia que aunque mejoró la balanza de pagos, incluso con superávit, no genera divisas en montos suficientes para aliviar el peso de la deuda y promover el desarrollo. Es decir, garantiza pagos pero no inversiones, de otro modo, soluciona el problema financiero internacional pero agrava la crisis latinoamericana. Así, mucho más que el monto de la deuda, es más grave su contexto internacional, mientras en 1982 la estabilidad y el desarrollo de las finanzas mundiales estaban estrechamente relacionados con la capacidad de pago latinoamericana, hubo argumentos y condiciones para demandar recursos frescos.

Hoy todo es distinto, las finanzas mundiales exhiben una solidez que les permite asimilar las medidas de presión y disuasión latinoamericanas, razón de más para insistir en reformular el sector externo latinoamericano, pues no es mucho lo que se puede esperar de la "ayuda" internacional, como no sea penetrar los mercados con

(5) Consultar "El Decenio de la Insoportable Deuda". The New York Times, Publicado en Summa, Abril-mayo $17 / 88$. una vigorosa política de exportaciones.

\section{Cepalismo y comercio exterior}

En este orden de ideas, es pertinente debatir los alcances y limitaciones atribuidos al comercio exterior por uno de los modelos de análisis que más ha influido en la estrategia de desarrollo latinoamericano. Se trata del cepalismo. Como se verá, no obstante el buen recibo del neo-liberalismo en las autoridades económicas de la subregión y de la crítica que aun desdela Cepal objeta el cepalismo, éste sigue ejerciendo poderosa influencia orientada hacia el aislacionismo económico internacional, en otras palabras, desestimula, cuando menos, el desarrollo del sector externo. Para tratar el caso se comentarán brevemente algunos de los enunciados cepalinos que guardan más estrecha relación con el comercio internacional, a saber: la concepción centro-periferia, tanto en su acepción estática como dinámica, la industrialización, el proteccionismo, la integración latinoamericana y el financiamiento externo ${ }^{(1)}$.

Como es bien sabido, el cepalismo posee un enfoque que incluye lo sistémico y lo estructural, de modo que la problemática latinoamericana se aborda dentro de un marco global materializado en el sistema económico internacional dentro del cual operan relaciones de intercambio con y entre estructuras económicas accesibles al análisis. Dicho en otros términos, el sistema económico internacional lo integran estructuras económicas conocidas como centros y periferias. Se afirma además, que la organización interna de centros y periferias difiere sustancialmente, surge así el

(6) Sobre Cepalismo consultar: "La Teoria del Subdesarrollo de la Cepal". Octavio Rodriguez. Siglo XXI editores. 1986. 
concepto de "asimetría estructural". En los primeros la producción es "diversificada" y "homogénea", con ello se entiende que el aparato económico desarrolla todos sus sectores: el primario, el secundario y el terciario. La homogeneidad califica la universalización de una base productiva altamente tecnificada y con relaciones capitalistas de producción. En contraste asimétrico la periferia es especializada (desarrollo de un solo sector) y heterogénea (yuxtaposición de niveles técnicos y de relaciones productivas). En principio, el origen de esta configuración (centro y periferia) se explica por el retardo histórico de algunos países (la periferia) para definir su desarrollo bajo el patrón capitalista. Ahora bien, sobre la base de la tendencia expansiva de los centros y las carencias de la periferia, los polos del sistema ponen en juego el intercambio comercial. Este análisis constituye el aspecto dinámico de la concepción centro-periferia. Según la Cepal ese intercambio es desigual (asimétrico) y desventajoso para los países periféricos, incluida Latinoamérica. Esto lo explica la Cepal aduciendo que el comercio en condiciones asimétricas pone en marcha lo que denomina la "tendencia al deterioro en los términos de intercambio" para la periferia. Gráficamente esto significa que mientras las exportaciones periféricas tienden a bajar de precio, las importaciones del centro tienden al alza, de modo que cada vez se necesitan más unidades exportables para adquirir la misma unidad importable.

La conclusión es obvia: a través del intercambio comercial los centros se apropian de más y más trabajo periférico, o bien, es tanto como decir que en las relaciones comerciales la "asimetría estructural" no sólo se reproduce, también se dilata, lo cual sugiere que la asimetría centro-perife- ria tiene su verdadero origen en el intercambio y no así tanto en el retardo histórico. Evidentemente, esta no es una visión positiva del comercio internacional, no reporta beneficios a los países periféricos. Así que implícitamente en materia de comercio exterior lo que se propone es el aislacionismo. Este resulta ser el presupuesto básico de la conocida tesis del "desarrollo hacia adentro", más concretamente, industrialización para el mercado interno. Su argumentación expresa lo siguiente: El proceso de industrialización procede por intermedio de la sustitución de importaciones, la importación de bienes finales para el consumo es sustituida por la importación de maquinaria, equipos y tecnología.

Obviamente, estas importaciones presionan el déficit en la balanza comercial toda vez que se trata de una industria que no genera divisas pero sí las consume. En estas condiciones es imperiosa la intervención del Estado para controlar el comercio de importación y prevenir el colapso del fondo de divisas. Este orden de procedimientos saca nuevamente a flote el sesgo aislacionista: de un lado, la industrialización hacia adentro la descarta como fuente generadora de divisas. De otro, el estrecho fondo de divisas aportadas por el sector primario impone rígidos y selectivos criterios de importación que aislan aún más la periferia del centro debido a la reacción proteccionista de estos. En conclusión, más que alcances son límites lo que asignó el rol del mercado interno a la industria, la privó de su potencialidad externa. En esto jugó papel muy importante la política proteccionista de la Cepal. Allí se elaboró el concepto de "Asimetría de la protección". Bajo esta directriz la periferia se ha empeñado en obtener la reducción de aranceles a sus exportaciones y la protección para su 


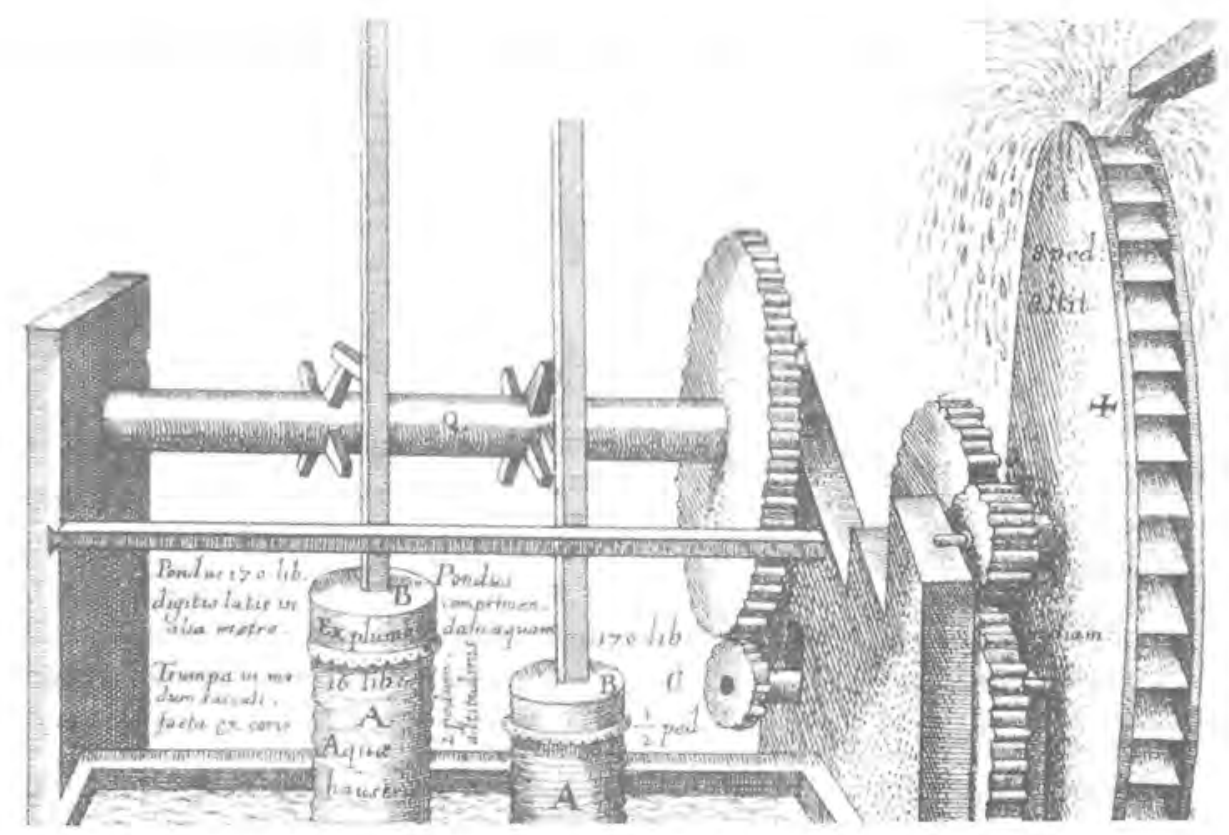

industria. Los resultados están hoy a la vista. Un sector externo limitado a unos pocos renglones primarios y una industria ineficiente para la competencia externa. Prueba de ello es que la participación de las manufacturas en las exportaciones latinoamericanas es muy baja; para Brasil, que ostenta la mejor posición, sólo aportaron en 1978 el 29\%, para Argentina el $13 \%$, Venezuela el $11 \%$, México el $10 \%$, Chile el 9\%, Colombia el 3\%," De entonces acá no es mucho lo que ha variado el panorama. En 1985, para el conjunto latinoamericano, las manufacturas aportaron el $16 \%$. En Asia, el 54\% ${ }^{\text {in }}$.

La integración latinoamericana es quizás el área temática más específica sobre comercio internacional dentro del pensamiento cepalino, al mismo tiempo constituye la directriz de más plena vigencia en tanto

(7) Jacqueline Roddick. op.cit pág. 129.

(8) Consultar: "Las Politicas de Comercio Exterior en América Latina". Informe de Naciones Unidas. Publicado en: "Economia Colombiana". No. 171 Julio 1985. considera la posibilidad de aprovechar positivamente el potencial de comercio regional. Sin embargo, sólo le atribuye alcances limitados. Para empezar, ese comercio, más que cualquier otra cosa, es comercio intra-periférico, su presupuesto de fondo insiste que con las economías centrales se arriesga la tendencia al deterioro en los términos de intercambio. Más aún, partiendo de considerar la conveniencia de un comercio intra-periférico parece que tampoco es concebido como auténtica política para el desarrollo, como que no se trata de impulsar por su intermedio una economía de productividad, calidad y eficiencia de rango competitivo. En su lugar, ese comercio es sólo una posibilidad puntual de reducir esos márgenes de capacidad ociosa que el mercado interno no alcanza a realizar. Es verdad que a eso se añade como subproducto del comercio regionalperiférico la posibilidad de exportar manufacturas al resto del sistema, pero no cabe duda que la formulación del objetivo prin- 
cipal no dispone a la integración de alcances suficientes que reclamen la adopción de políticas y mecanismos para eventos que estén más allá de la exportación de excedentes. Por lo demás, el pobre balance del comercio regional así lo refrenda, y resulta incluso muy sintomático que un estudio efectuado por la Aladi sobre limitaciones y obstáculos al comercio intrarregional de productos básicos agropecuarios destaque los siguientes aspectos:

1. Precios no competitivos con la oferta internacional.

2. Desconocimiento de licitaciones, concursos o contratos.

3. Desconocimiento de la situación de excedentes y faltantes.

4. Desconocimiento de las normas de las bolsas de productos básicos.

5. Inexistencia de financiamiento convencional.

6. Estructuras productivas similares con excedentes en los mismos productos.

7. Existencia de subsidios al consumo que limitan el comercio.

8. Falta de respaldo politico o de directrices expresas que faciliten la negociación con otros paises de la región.

9. Disminución del intercambio por escasez de divisas.

10. Falta de un buen funcionamiento del sistema de pagos recíprocos.

11. Existencia de barreras arancelarias y de restricciones no arancelarias cada vez más proteccionistas ${ }^{y}$.

(9) Consultar: "El Mercado Regional como Estímulo y Factor del Desarrollo Latinoamericano. Washington Herrera. Publicado en "Relaciones Económicas Internacionales de América Latina", compilación del Sela. Editorial Nueva Sociedad, 1987.
Como se puede observar, no se dispone siquiera de conocimientos, mecanismos, organización e infraestructura para un activo comercio regional.

Tanto como el comercio de bienes, para el comercio de capitales (endeudamiento externo) de nuevo la Cepal propugna por el aislacionismo. En primer lugar se subraya que debe ser un recurso transitorio. En segundo lugar, debe establecerse preferiblemente con organismos multilaterales. Desde luego son plausibles los argumentos en la medida que adviertan sobre los peligros de una desaconsejada política de endeudamiento, pero es políticamente poco realista prescindir de la banca comercial.

En realidad, el riesgo de terminar prestando para pagar amortizaciones y servicios sólo se explica bajo el supuesto de que el endeudamiento es un recurso para financiar inversiones que no generan divisas, es directo resultado del aislamiento económico inspirado por el cepalismo.

\section{Conclusiones}

La crisis de endeudamiento externo puede constituirse si hay voluntad política para ello, en una oportunidad histórica de rediseñar el patrón de inserción en la economía mundial y las propias condiciones de acumulación interna latinoamericana. Estos serían los beneficios derivados de fortalecer el sector externo de nuestras economías. El logro de este propósito conlleva sin embargo, el costo de remover los obstáculos que para el comercio internacional se han creado alrededor del modelo cepalista de industrialización para el mercado interno, y de emprender con audacia a nivel productivo y organizacional la proyección de la economía en el mercado internacional. 


\section{Bibliografias}

\section{Algunos elementos geopolíticos del Pacto Cafetero}

ARANGO, Mariano. El Café en Colombia. Carlos Valencia Editores, Bogotá, 1982.

NIETO Arteta, Luis Eduardo. El Café en la sociedad colombiana, coedición ECOE, Bogotá, 1975.

OCAMPO, José Antonio -editor. Lecturas de economía cafetera. Tercer mundo y Fedesarrollo, Bogotá, 1987.

PALACIOS, Marco. El Café en Colombia 1950-1970. El áncora editores, México, 1983.

RAMIREZ Ocampo, Jorge y PEREZ, Silverio, 83 años de política cafetera internacional y la participación de Colombia en este proceso. Federación, Bogotá, 1984.

REVEIZ, Edgar -Compilador-, La cuestión cafetera. Colección debates. CEDE, Bogotá, 1980.

FEDERACION BOGOTA. Propósitos de la industria cafetera 1850-1986. Junio 1987.

FEDESARROLLO. Debates de coyuntura económica No. 15 - El rompimiento del Pacto Cafetero, su impacto económico. Bogotá, 1989.

FEDESARROLLO. Coyuntura Económica Volumen XX No. 1. Marzo, 1990.

FEDESARROLLO Y FONDO CULTURAL CAFETERO. Economía Cafetera Colombiana. Bogotá 1980.

FEDERACION NACIONAL DE CAFETEROS. Ensayos sobre Economía Cafetera No. 4. Abril-septiembre, 1989.

CONTRALORIA GENERAL DE LA REPUBLICA Y UNIVERSIDAD NACIONAL. EI Fondo Nacional del Café, Bogotá, 1988.

Economía Colombiana No. 191-193 de abril de 1987 y 221 de septiembre de 1989.

Estrategia Económica y Financiera No. 114. Septiembre de 1987.

Revista Negocios No. 69. Agosto de 1989.

Revista Nueva Frontera No. 740. Junio de 1989.

Revista Nueva Frontera No. 793. Julio 30 de 1990.

Revista Semana No. 372. Junio de 1989.

Revista Javeriana No. 548. Septiembre de 1988.

Enciclopedia Nueva Historia de Colombia. Editorial Planeta. Bogotá, 1989.

Publicaciones de la Federación Nacional de Cafeteros.

\section{Deuda Externa y Comercio Exterior.}

AUTORES VARIOS: Los Traficantes de la Pobreza. El F.M.I. y América Latina. El Ancora Editores. Bogotá, 1984.

SILVA Colmenares, Julio. Deuda Externa. Crisis y Confrontación. Ediciones Alborada. Bogotá, 1988.

OCAMPO, José Antonio y LORA, Eduardo. Colombia y la Deuda Externa. Tercer Mundo Editores. Bogotá, 1988. 
GARAY S., Luis Jorge. La Iniciativa Brady en la Evolución de la crisis de la deuda. Fescol. Bogotá, 1989.

RODDICK, Jacqueline. El Negocio de la Deuda Externa. El Ancora Editores. Bogotá, 1990.

\section{ARTICULOS:}

LOS BANCOS COMERCIALES Y EL DESARROLLO DE LA PERIFERIA: CONGRUENCIA Y CONFLICTO. Robert Devlin. Revista de La Cepal No. 9. Santiago de Chile, 1979.

RENEGOCIACION DE LA DEUDA LATINOAMERICANA: UN ANALISIS DEL PODER MONOPOLITICO DE LA BANCA. Robert Devlin. Revista de La Cepal No. 20. Santiago de Chile, 1983.

EL ESCENARIO INTERNACIONAL Y LA DEUDA EXTERNA DE AMERICA LATINA. Luciano Tomassini. Revista de La Cepal No. 24. Santiago de Chile, diciembre 1984.

POLITICA EXTERIOR Y NEGOCIACION FINANCIERA INTERNACIONAL: LA DEUDA EXTERNA Y EL CONSENSO DE CARTAGENA. Jorge E. Navarrete. Revista de La Cepal No. 27. Santiago de Chile, diciembre 1985.

EL PAPEL DE LAS ORGANIZACIONES MULTILATERALES EN LA RENEGOCIACION DE LA DEUDA. Hugo E. Souza, Revista Integración Latinoamericana. Enero-febrero 1986.

EL IMPACTO DE LA CONVERSION DE DEUDA EN CAPITAL. Michael Blackwell y Simón Nocera. Revista Finanzas y Desarrollo. Junio 1986.

LA DEUDA EXTERNA ÚN MENU DE OPCIONES PARA LOS PAISES DEUDORES. Robert Devlin. Revista Economía Colombiana No. 211-212. Noviembre-diciembre 1988.

DEUDA EXTERNA EN AMERICA LATINA Y EL CARIBE. Sela. Revista Economía Colombiana No. 211-212. Noviembre-diciembre 1988.

LA EVOLUCION DEL PROBLEMA DE LA DEUDA EXTERNA EN AMERICA LATINA Y EL CARIBE. Estudios e Informes de la Cepal. Santiago de Chile 1988.

DISYUNTIVAS FRENTE A LA DEUDA EXTERNA. Robert Devlin. Revista de La Cepal No. 37. Santiago de Chile. Abril, 1989.

\section{Reestructuración económica y ventaja comparativa dinámica}

BALCAZAR, A.V. Tecnología y crisis de la agricultura en Colombia. Economía Colombiana. 72-81.

BHAGWATI, J. Some recent trends in the pure theory of international trade. In International Trade Theory in a Developing World by Harrod R. \& D. Hague (1964), 1-30.

CALVO, H.S. \& M. MARTINEZ. La ventaja comparativa de la industria manufacturera colombiana. Bogotá, Proexpo, 1973, $40 \mathrm{p}$.

FRANSMAN, M. \& K. KING. Technological capability in the Third World. Macmillan, 1984, 404 p.

GUPTAL, L.C. Growth theory and strategy: new direction. Delhi, Oxford University Press, 1983, 162 p.

JOHNS, R.A. International trade theories and the evolving international economy. London, Frances Pinter, $1985,321 \mathrm{p}$.

JOHNSON, H.G. Effects of changes in comparative costs as influenced by technical change. In International Trade Theory in a Developing World by HARROD, R, \& D. HAGUE (1964), 96-112.

Factor endowments, international trade, and factor prices. In Readings in International Economics by American Economic Association (1968), 78-89.

KRUGMAN, P.R. (ed). Strategic trade policy and the New International economics. Cambridge, Mass., The MIT Press, 1987, 313 p.

LORA, E.T. Revisión de las teorías mercantilistas y clásicas sobre el comercio internacional. Cali, CIDSE, Monografia No. 1,60 p. 
MEIER, G.M. International trade and development. New York, Harper \& Row, 1963, 208 p. Cap. 2 Comparative Costs, 9-39.

NELSON, R.R. \& S.G. WINTER. An evolutionary theory of economic change. Harvard University Press, $1982,437 \mathrm{p}$.

PERRY, G.E. Políticas selectivas de promoción a las exportaciones. Coyuntura Económica, Vol. 8, No. 4, dic. 1978, 143-166.

ROBINSON, R. Factor proportions and comparative advantage. In Readings in International economics by American Economic Association (1968), 3-23.

ROJAS, G.L. Tipo de cambio y exportaciones agropecuarias. Boletín Socioeconómico (Cali, CIDSE, marzo 1987), No. 17, 51-71.

RYBCZYNSKI, T.M. Factor endowment and relative commodity price. In Readings in international economics by American Economic Association (1968), 72-77.

SAMUELSON, P.A. International factor price equalization once again. Ibidem, 58-71.

THOUMI, F. Estrategias de industrialización, empleo y distribución de empleo en Colombia. Coyuntura Económica, Vol. 9 No. 1, abril 1979.

VASQUEZ, E. Comentarios en torno al uso de la "Tecnologia" en las teorías económicas. Boletín Socioeconómico (Cali, CIDSE, marzo 1987), No. 17, 7-32.

\section{Condiciones para la participación humana en la Empresa}

TAYLOR, Frederick. Principios de Administración Científica.

MAYO, Elton. The social problem of an Industrial Civilization. Boston, Harvard, University Press, 1933.

MC GREGOR D. El aspecto humano de la Empresa. Nueva York, McGraw-Hill, 1960.

MONROY. Leonal. Las Etapas del Desarrollo del Ser Humano y su relación con el desarrollo del personal en las Organizaciones. Revista "Cuadernos de Administración". Universidad del Valle. Año 4, Noviembre 12, 1985.

SEVILLA. Andrés. Conferencias Mimeografiadas. Carvajal S.A. 